Int. J. Dev. Biol. 57: 159-168 (2013)

doi: $10.1387 / \mathrm{ijdb} .130047 \mathrm{av}$

\title{
Role of cyclins in controlling progression of mammalian spermatogenesis
}

\author{
DEBRA J. WOLGEMUTH* ${ }^{* 1,2,3,4}$, MARCIA MANTEROLA ${ }^{1}$ and ANA VASILEVA ${ }^{1,5}$ \\ ${ }^{1}$ Departments of Genetics \& Development and ${ }^{2}$ Obstetrics \& Gynecology, ${ }^{3}$ Institute of Human Nutrition, \\ ${ }^{4}$ Herbert Irving Comprehensive Cancer Center and ${ }^{5}$ Center for Radiological Research, \\ Columbia University Medical Center, New York, NY 10032, USA
}

\begin{abstract}
Cyclins are key regulators of the mammalian cell cycle, functioning primarily in concert with their catalytic partners, the cyclin-dependent kinases (Cdks). While their function during mitosis in somatic cells has been extensively documented, their function during both mitosis and meiosis in the germ line is poorly understood. From the perspective of cell cycle regulation there are several aspects of mammalian spermatogenesis that suggest unique modes of regulation and hence, possible unique functions for the cyclins. This review will summarize our current understanding of cyclin expression and function in the male germ line, with particular focus on the $A$ and $E$ type cyclins in the mouse model. While the focus is on mammalian spermatogenesis, we note contrasts with similar functions in the female germ line when relevant and also draw upon observations in other model systems to provide further insight.
\end{abstract}

KEY WORDS: cyclin, cell cycle, meiosis, spermatogenesis

\section{Overview}

Spermatogenesis in the adult animal is a complex process of differentiation that may be divided into three phases by the kinds of cells that are found-the mitotic phase represented by spermatogonia, the meiotic phase by spermatocytes, and the haploid phase or spermiogenesis by spermatids. From the perspective of cell cycle regulation, there are many aspects of this process that present unique control points that are simply not found in somatic cells. This review will begin with a brief overview of the current status of our understanding of cell cycle regulation in somatic cells, with a particular focus on the function of the cyclin proteins. We next highlight various aspects of spermatogenesis in the mouse model that pose particular questions unique to cell cycle regulation in the male germ line. We will then summarize work from our lab and that of others as to what is known about the expression and function of the cyclins in the male mammalian germ line, with an emphasis on the A- and E-type cyclins that are more extensively studied than the other cyclins. Although our focus is on the mammalian model system, we will refer to interesting observations from other genetic model systems as they could provide insight into the function of the cyclins in the germ line of higher eukaryotes.

\section{Cyclins: key components of the cell cycle machinery}

Cellular proliferation requires passage through a cell cycle wherein a cell replicates its DNA and segregates it into two daughter cells. One of the most important functions of the cell cycle is to maintain genetic stability during the process of generating new cells. Thus, the key cellular machinery controlling cell cycle progression must ensure that chromosomal DNA is precisely duplicated, repaired and segregated to the new cell generation. This machinery is comprised of a complex between regulatory proteins known as cyclins and their catalytic subunits the cyclindependent kinases (Cdks) (the reader is referred to several more comprehensive reviews on the topic of cell cycle regulation upon which this overview is based (Bloom and Cross, 2007, Blow and Dutta, 2005, Malumbres and Barbacid, 2005, Moroy and Geisen, 2004, Satyanarayana and Kaldis, 2009, Wolgemuth, 2011)). Cyclins regulate the activity of their Cdk partners and also modulate their substrate specificity. More than 20 Cdk-related proteins and

Abbreviations used in this paper: cdk, cyclin-dependent kinase; E, embryonic; MPF, maturation promoting factor; pnd, post-natal day.

\footnotetext{
*Address correspondence to: Debra J. Wolgemuth, PhD. Department of Genetics and Development and Obstetrics \& Gynecology, Columbia University Medical Center, Russ Berrie 608, 1150 St. Nicholas Avenue, New York, NY 10032, USA. Tel: +1-212-851-4754. Fax: +1-212-851-5236. e-mail: djw3@ columbia.edu
}

Final, author-corrected PDF published online: 5 June 2013.

ISSN: Online 1696-3547, Print 0214-6282 


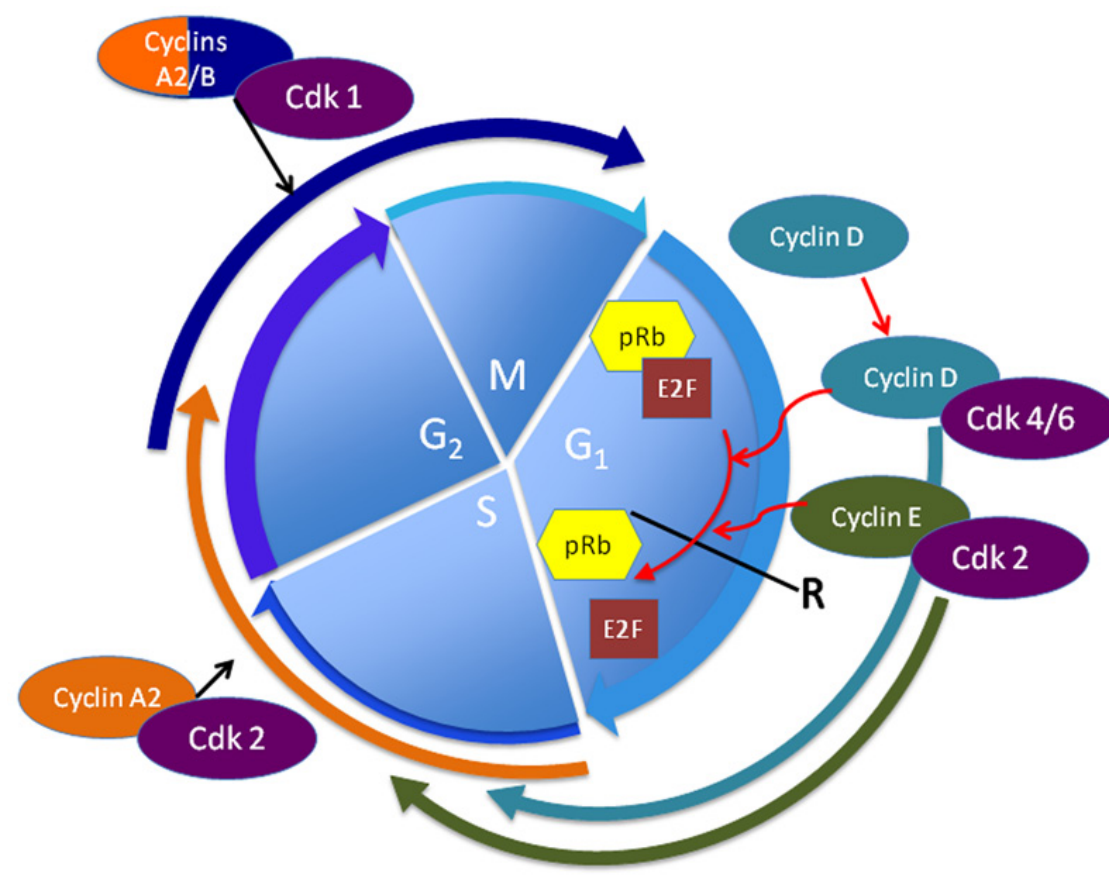

Fig. 1. Classical model of the mitotic cell cycle. $G 1$ phase is initiated by cyclin D binding and activation of Cdk4/6 kinases. The active cyclin D-Cdk4/6 complexes phosphorylate the retinoblastoma protein $(p R b)$ and the $p R b$-related proteins $p 107$ and $p 130$. When $p R b$ is phosphorylated, its interaction with the transcription factor E2F is abolished. The free E2F stimulates cyclin E synthesis. Cyclin E then binds to Cdk2 to form cyclin E-Cdk2 complex and together with cyclin D-Cdk4/6, increase pRb phosphorylation, liberating additional amounts of E2F sufficient to induce entry into $S$ phase of the cycle. Targets of E2F are also cyclin A2 and many $S$ phase specific genes, which ultimately lead to the G1/S transition. Cyclin A2 binds Cdk2 and promotes both G1/S and S/G2 transitions as well as DNA replication. Later cyclin $A 2$ and cyclin B bind Cdk1 and function at the G2/M transition and initiate mitosis.

is there dephosphorylation of $\mathrm{Rb}$ and inhibition of E2F in early $\mathrm{G} 1$ or in cells arrested in G0.

The mitotic A-type cyclin, cyclin A2, is synthesized at the onset of S-phase and like the E-type cyclin binds and activates Cdk2, thus promoting progression through S-phase via phosphorylation of proteins involved in DNA replication. During the G2/M transition, cyclin A2 complexes with Cdk1, prior to B-type cyclin expression. Subsequently, B-type cyclins bind to Cdk1 and drive entry into M-phase, culminating in the completion of the cell cycle.

Knockout mouse models have been generated for most of the major cell-cycle regulators (reviewed in (Satyanarayana and Kaldis, 2009)). Characterization of these mouse models revealed that surprisingly, except for cyclin A2, cyclin B1 and Cdk1, other cyclins and Cdks, originally thought to be essential for mitotic cell cycle regulation, are in fact largely dispensable. Lack of cyclin A2 and cyclin B1 resulted in early embryonic lethality, which argues that they are non-redundant. Cdk1, in complex with several of the major mitotic cyclins, had been proposed to be a master regulator of the mammalian cell cycle (Santamaria et al., 2007), and indeed, loss of Cdk1 function is incompatible with life. In contrast, loss of Cdk2 function only affected the progression of meiotic prophase in both the male and female germ lines (Berthet et al., 2003, Ortega et al., 2003).

In addition to activating and conferring substrate specificity to Cdks, some mammalian cyclins exhibit kinase-independent functions. For example, cyclin D1 can interact with transcription factors and act as a co-activator (Zwijsen et al., 1997). A kinaseindependent function has also been reported for

more than 11 cyclins have been identified in more complex eukaryotes, which has led to the concept that different cell cycle events are regulated by distinct cyclin-Cdk complexes. The sequential activation and deactivation of cyclin-Cdk complexes during cell cycle progression is tightly regulated and involves activating and inhibitory proteins, sub-cellular localization, and timely synthesis and degradation (for comprehensive reviews, see (Malumbres and Barbacid, 2005, Vermeulen et al., 2003)).

Studies on the four major classes of mammalian cyclins - the A-, B-, D-, and E-type cyclins-during mitosis have established a classical model for regulation of the cell cycle that places each cyclin-Cdk complex at a particular phase of the mitotic cycle (Fig. 1). For example, the D-type cyclins bind either Cdk4 or Cdk6 and regulate the transition from G0 to the G1 phase. Cyclin D-Cdk complexes phosphorylate $\mathrm{pRb}$ bound to $\mathrm{E} 2 \mathrm{~F}$, leading to the release of active E2F which activates transcription of genes needed for passage into $S$ phase, including genes encoding cyclins $E$ and $A$, Cdk2, and itself.

The E-type cyclins function during late $\mathrm{G} 1$ and throughout $\mathrm{S}$ phase, mainly in complex with Cdk2. In late G1 phase cyclin ECdk2 (along with cyclin D-Cdk4/6) phosphorylates proteins such as pRb, p107 and p130 to promote entry into S phase. To maintain productive cell cycle progression at later phases (S-phase, G2, and mitosis) cyclin-Cdk complexes continue to phosphorylate $\mathrm{Rb}$ and only after degradation of the mitotic cyclins at the end of M-phase cyclin E1 in that loading of MCM helicase onto DNA pre-replication complexes and entry into S-phase was observed in kinase-dead cyclin E-Cdk2 complexes (Geng et al., 2007).

Recent studies in Drosophila melanogaster report novel, non-cell cycle related roles for several cyclins. For example, reduced levels of the single Drosophila A cyclin in postmitotic neurons promote sleep, as evidenced by a delayed wake-sleep transition (Rogulja and Young, 2012). The abundance of cyclin A was also implicated in the regulation of the number of endocycles, in which repeated rounds of DNA replication occur without intervening mitoses, in mechanosensory organs in Drosophila (Salle et al., 2012). In male germ line stem cells of the fly, cyclin A (Wang et al., 2010) normally localizes to the spectrosome, and the par-1 mutant displays an aberrant localization pattern while its overexpression leads to defects in the centrosome orientation checkpoint.

\section{Unique aspects of spermatogenesis from a cell cycle perspective}

In mammals, spermatogenesis is considered to begin during embryonic development with the establishment of the primordial germ cells (PGCs) and their migration to the gonadal ridge. In the mouse, PGCs arise in the extraembryonic mesoderm at around E6.5 and migrate through the developing hindgut endoderm by E8.5, eventually colonizing the genital ridges at around E10.5. At 
this point and up to E12.5, the gonocytes of both sexes are proliferating. At $\sim \mathrm{E} 12.5$, the female gonocytes or oogonia begin to enter the pre-leptotene stage and progress through meiotic prophase. By E18.5, all oocytes are arrested at the diplotene stage of meiosis where they will remain until puberty followed by the cyclical entry into oocyte maturation characteristic of the reproductive span in the adult female.

In contrast, the male gonocytes continue to proliferate untilE15.5, at which time they enter a quiescent period that extends into the early post-natal period. At approximately post-natal day (pnd) 3, the quiescent gonocytes resume proliferation and a subset give rise to undifferentiated type Aspermatogonia (for a comprehensive review on spermatogonial differentiation, see (de Rooij and Russell, 2000)). The more undifferentiated type $A$ spermatogonia are subdivided into three types, $A_{\text {single }}(A s), A_{\text {paired }}(A p r)$, and $A_{\text {aligned }}$ (Aal). The As population is generally considered to constitute the spermaogonial stem cells (SSCs) and, like other stem cells, has the capability to both self-renew and to differentiate into committed progenitors. Apr cells divide to form the Aal spermatogonia that can be found in clones of Aal 4 to 16 (occasionally 32). These clones of Aal 4-16+ are presumably committed to differentiation and are followed by the A1-4, Intermediate (In) and B spermatogonia. However, the SSC pool may actually consist not just of As, but also of a subset of the Apr cells, and even Aal in chains of 4 or more, which have recently been shown to contribute to the self-renewing SSC pool (Morimoto et al., 2009). Thus, undifferentiated spermatogonia may be unique among adult stem lineages, possessing greater renewal potential than other adult stem cells. In addition, there is heterogeneity within the As population - As cells that stained lightly or more intensely with toluidine blue had been described by Martin Dym and colleagues (Dettin et al., 2003). Oatley et al., recently reported that the inhibitor of DNAsysnthesis protein ID4 is the only marker expressed uniquely in As cells (Oatley et al., 2011). They further noted that within the Id4+ type As, there were two populations, those that were Id4+/ Plzf-and those that were Id4+/PIzf+. These observations suggested that there are two classes of SSCs, perhaps reflecting that those quiescent serve as a reserve pool while the more actively dividing SSCs contribute to normal spermatogenesis.

Another interesting aspect of cell cycle regulation in the male germ line occurs at the Aal to A1 spermatogonia transition: this step occurs in the absence of replication and cell division and rather, is driven at least in part by retinoic acid (Gaemers et al., 1996). The mitotic divisions that follow produce the differentiated A1-4, Int, and $B$ spermatogonia, which are now synchronous. The number of divisions is tightly regulated and species specific. Interestingly, the level of cell cycle synchrony among these divisions is perhaps the most tightly regulated in any model system of mammalian differentiation (Dirk de Rooij, personal communication). Once the spermatogonia transition from Aal to $A 1$, there is no indication that these differentiated cells can revert to a stem cell-like status.

Following the differentiation to B spermatogonia, the cells enter meiosis, a process that by every standard constitutes a highly specialized cell cycle. The spermatocytes pass sequentially through the pre-leptotene, leptotene, zygotene, pachytene, and diplotene phases of prophase I and then quickly undergo the two M-phase divisions, ultimately yielding haploid cells, the spermatids. The S-phase that occurs in pre-leptotene spermatocytes is followed by an extremely protracted intervening meiotic prophase before entry into M-phase. The events that occur during this phase are common to both spermatocytes and oocytes, including synapsis, recombination, etc. However, the timing of this phase is strikingly different, both in terms of duration and stages of development of the animal. Unlike oocytes, which arrest at the diplotene stage until the resumption of meiotic maturation, the metaphase divisions of spermatocytes occur in rapid sequence to produce the haploid spermatids. The occurrence of two successive nuclear divisions, without an intervening round of DNA synthesis, is another feature unique to the meiotic as compared to mitotic cell cycle and is common to both male and female meiosis. The transition from prophase to M-phase of meiosis I is similar to the G2-M transition in the mitotic cell cycle, although adapting this transition for the meiotic cell cycle requires several significant modifications in cellular and molecular events. Separation of homologues, rather than sister chromatids, and timing considerations, such as dictyate arrest in oocytes, are just some of the unique features of meiotic cells at this transition, and the cellular machinery must adapt to regulate and monitor such events.

\section{A-type cyclins}

\section{Expression and function of the A-type cyclins}

The mammalian A-type cyclins have been studied extensively

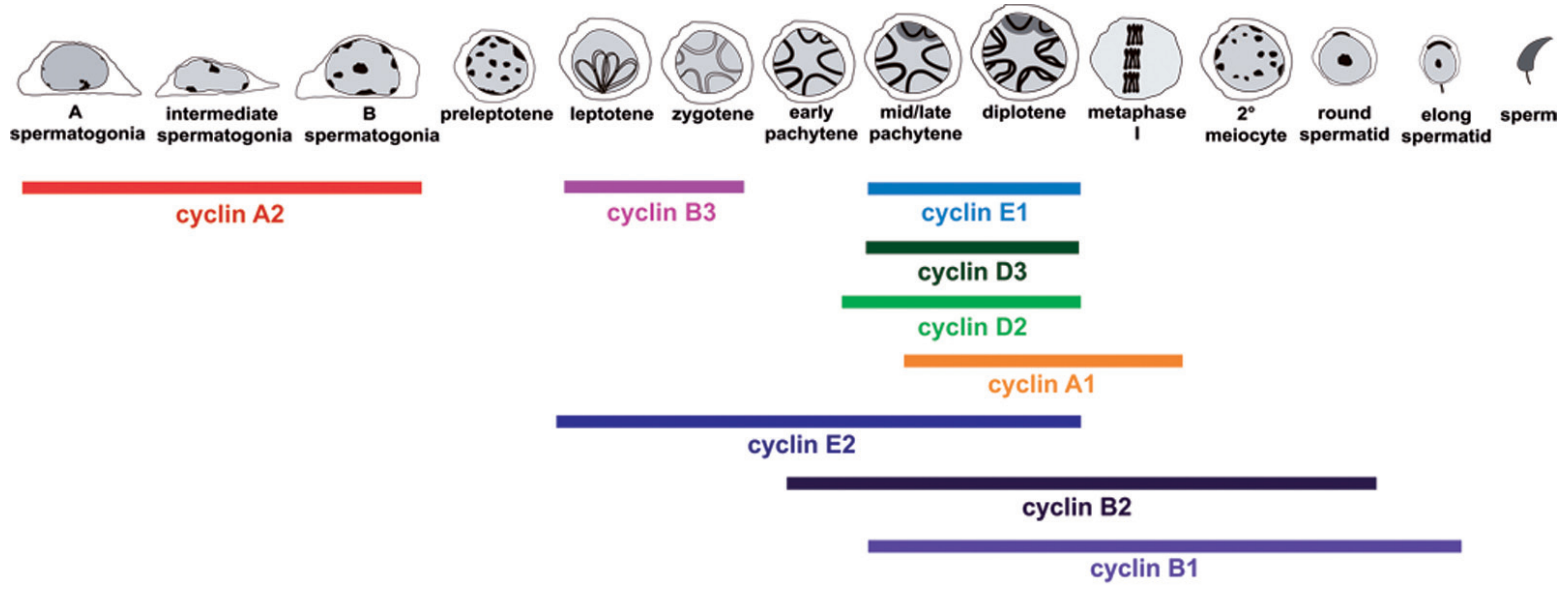

Fig. 2. Cyclin expression during mammalian spermatogenesis. Colored bars indicate the expression of each cyclin in the different cell types, as has been reported at the mRNA and/or protein level. 
in the somatic lineage but their distinct pattern of expression in the male germ line remains one of their most intriguing features. Unlike other cyclin families which are comprised of redudndant multiple members, both of the two A-type cyclins are uniquely essential (for comprehensive review, see (Wolgemuth, 2011)). The originally identified A-type cyclin, now designated cyclin A2, is ubiquitously expressed in cultured cells, in the developing embryo and in virtually all tissues that have dividing cells, and is up-regulated in a variety of cancers. Perhaps not surprisingly, targeted mutagenesis of the murine Ccna2 gene resulted in early embryonic lethality, apparently around the peri-implantation stage (Murphy et al., 1997). We discovered that in addition to Ccna2, mammals contain a second gene, cyclin A1 (Ccna1), which in striking contrast to Ccna2, is restricted specifically to the male germ line (Ravnik and Wolgemuth, 1996, Sweeney et al., 1996). Mouse cyclin A1 mRNA and protein are detected only in late pachytene to diplotene spermatocytes but not at significant levels during the second division of male meiosis (Fig. 2) (Sweeney et al., 1996). We tested the hypothesis that the primary site of Ccna1 function is in the male germ line, specifically at the first meiotic division by generating cyclin A1-deficient mice by targeted mutagenesis of the Ccna1 gene (Liu et al., 1998). Ccna1- mice were viable, however the males were sterile and histological and cytogenetic analysis revealed an absence of germ cell differentiation beyond the late diplotene stage. Assessment for apoptosis by TUNEL assay showed a massive wave of cell death in diplotene cells and confirmed the point of arrest in cyclin A1-deficient spermatocytes to the diplotene-metaphase 1 transition. These studies demonstrated the absolute requirement for cyclin A1 in late prophase I spermatocytes in order to enter metaphase I. In both mitosis and meiosis, the transition into metaphase is regulated by activation of the maturation promoting factor (MPF), a complex composed of Cdk1 kinase and a B-type cyclin. In the stages leading up to this transition, cyclin B accumulates in the cell and Cdk1 is activated by cyclin dependent kinase activation kinase (Cak) and by dephosphorylation via Cdc25 phosphatase. The activation of Cak in mitotic cells, associated with build up of

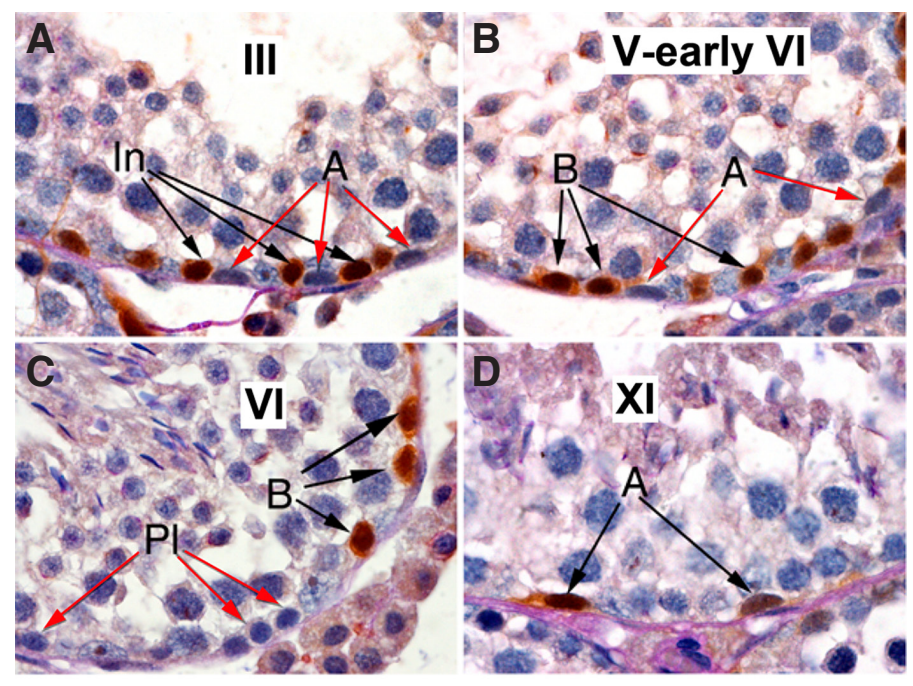

Fig. 3. Expression of cyclin A2 in spermatogonia of adult testis (arrows). Stages of tubules are indicated by Roman numerals; spermatogonia subtypes are indicated with the corresponding letters, as described in the text. mitosis-specific cyclin A2, results in the initiation of metaphase I. We speculated that cyclin A1 activates meiotic metaphase transition during meiosis I, in conjunction with MPF. There was a striking reduction in the activation of MPF kinase at the end of meiotic prophase, although both $\mathrm{Cdk} 1$ and cyclin $\mathrm{B}$ proteins were present. The spermatogenic arrest, which occurs at the metaphase transition, is likely to be due to impaired Cdk1 kinase activation and spindle checkpoint activation (Liu et al., 2000). The apparent relatively normal appearance of the meiotic chromosomes was supported by subsequent studies in which pachytene cyclin A1deficient spermatocytes were artificially driven into a metaphase configuration by treatment with okadaic acid (Liu et al., 2000). Metaphase I preparations from mutant and normal spermatocytes appeared similar, with no obvious defects in chiasmata. Cyclin A1 is therefore essential for passage into the first meiotic division in spermatocytes, a function that cannot be complemented by the concurrently expressed B-type cyclins. Importantly, the arrest in meiosis phenotype appears to be unique to cyclin A1 and Cdk2 among the cyclins and Cdks that have been studied by mutational analysis in vivo.

Therefore, in the mouse model, both A-type cyclins are absolutely essential genes, cyclin A1 for male meiosis and A2 for embryonic development. The importance of understanding the regulation and function of the A-type cyclins in mammalian cells is underscored by the contrasts with highly studied yeast model systems, which totally lack this class of cyclins and Drosophila, another carefully mined model for cell cycle studies, which have only a single A-type cyclin.

Although we reported several years ago that cyclin A2 is expressed in spermatogonia (Fig. 2) (Ravnik and Wolgemuth, 1996, Ravnik and Wolgemuth, 1999), we have not established whether A2 expression is common to all spermatogonial subtypes. In addition, because of the early embryonic lethality of cyclin A2deficiency, its role in adult lineages remains to be determined. To narrow down precisely which types of spermatogonia express cyclin A2 we performed immunohistochemical analysis of staged tubules in adult testes (Fig. 3). Our analyses to date allow us to conclude that cyclin A2 is expressed in differentiated type A, In and type $B$ spermatogonia. There is also a pronounced difference in staining intensity between different types and possibly even among the same type of spermatogonia (Fig. 3D, stronger staining in left-most cell compared to right-most). This could reflect differential accumulation of cyclin A2 protein as cells progress from $\mathrm{S}$ to $\mathrm{M}$ phase of the cell cycle.

Precisely controlled mitotic divisions are essential for the proliferation and development not only of post-natal, but also embryonic germ cells. At E9.5, the migratory PGCs divide prolifically and populate the gonads by E11.5. In the male germ line mitotic divisions continue until E15.5 when the gonocytes arrest at G0 until spermatogenesis resumes several days after birth. We hypothesized that cyclin A2 may also be important for mitosis in the embryonic germ cells as well and therefore determined its localization in male gonads at E10.5, 13.5, 15.5, and 17.5 (Fig. 4). Although cyclin A2-positive PGCs at E10.5 are found infrequently, A2-positive gonocytes are readily detectable at E13.5, but are scarce by E15.5, likely reflecting their entry into a quiescent state. Therefore, we restricted our analysis between E9.5 and E15.5 as the detection of cyclin A2 in migrating PGCs prior to E9.5 will be quite challenging and its expression is not 


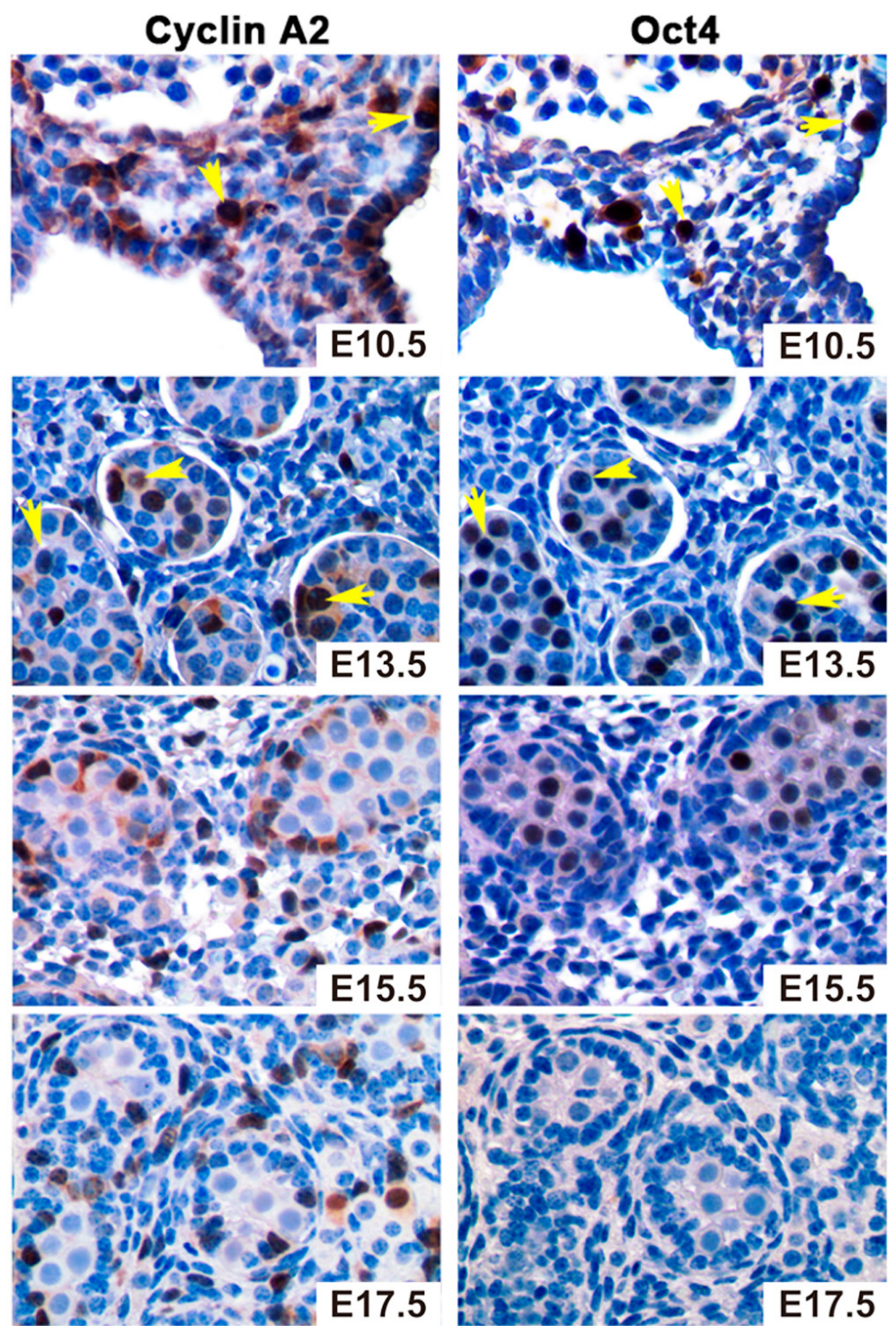

Fig. 4. Expression of cyclin A2 in embryonic testis. Sequential sections were stained with antibodies against cyclin A2 (left panels) and Oct4 (right panels). Gonocytes expressing both cyclin A2 and Oct4 are indicated with yellow arrows Nuclei are stained with hematoxylin.

robust in gonocytes beyond E15.5. We will, however, extend the analysis to examine gonocytes in post-natal testes at pnd1, 2, and 3, when spermatogonial proliferation resumes and determine if cyclin A2 expression resumes concomitantly.

Our recent studies generating cyclin A2 conditional knockout (A2CKO) mice have revealed several highly significant and paradigm-shifting observations concerning the role of cyclin A2 in cell cycle regulation (Kalaszczynska et al., 2009). First, mouse embryonic fibroblasts (MEFs) deficient of all A-type cyclins can undergo mitotic divisions. Second, up-regulation of cyclin $E$ apparently compensates for loss of all A-type cyclins in MEFs. Third, in contrast, our data have shown an absolute requirement for cyclin A2 by hematopoietic stem cells (HSCs) and embryonic stem cells (ESCs) for their proliferation. To determine if cyclin $\mathrm{A} 2$ is required for the proliferation of spermatogonial stem cells
(SSC) it will be essential to ascertain whether SSC express cyclin A2 and then to use Cre-expressing strains to excise floxed $\mathrm{A} 2$ alleles in the SSC.

\section{Regulation of expression of the A-type cyclins}

As noted above, the two A-type cyclins exhibit strikingly different patterns of expression: Ccna2 is ubiquitously expressed in mitotically dividing cells while expression of Ccna1 is highly restricted, being most abundant in the testis in both mice and humans (Liao et al., 2004, Sweeney et al., 1996, Yang et al., 1997). In mice, Ccna1 is expressed specifically in testis in stage IX to XII spermatocytes. We and others have now shown that human $C C N A 1$ is also expressed at highest levels in male germ cells. Ccna1 and Ccna2 also exhibit a distinct, non-overlapping pattern of expression during male germ cell development, as Ccna2 expression is down-regulated early in the meiotic cell cycle before Ccna1 is expressed (Ravnik and Wolgemuth, 1999, Sweeney et al., 1996, Wolgemuth, 2008). We therefore hypothesized that there are specific regulatory elements unique to each A-type cyclin that are critical for their distinct regulation of expression.

The human CCNA1 promoter contains a $1.3 \mathrm{~kb}$ region upstream of the starting site that controls the expression of a transgenic EGFP construct in a much less restricted pattern in male germ cells than seen for the endogenous Ccna1 gene (Muller-Tidow et al., 2003). The mouse Ccna1 promoter contains an upstream sequence $1.3 \mathrm{~kb}$ to $+0.8 \mathrm{~kb}$ of the putative transcriptional start site that is sufficient to recapitulate the endogenous pattern of Ccna1 expression (Lele and Wolgemuth, 2004). Specifically, we showed that transgenic mice with $\beta$-gal under the control of this region expressed $\beta$-galactosidase in spermatocytes at stages IX to XII of the cycle of the seminiferous epithelium, and not in earlier stages, similar to the narrow window of expression that was also observed with the endogenous mouse gene. A consensus sequence for two sets of paired CDE (cell cycledependent element)/CHR (cell cycle genes homology region) elements, also present in the CCNA2, CDK1, and CDC25C genes; and believed to control the timing of expression of these genes during the cell cycle (Zwicker et al., 1995), was identified in this $1.3 \mathrm{~kb}$ region.

Sequences between $4.8 \mathrm{~kb}$ and $1.3 \mathrm{~kb}$ upstream of the putative transcriptional start site of the mouse cyclin $A 1$ promoter also contain enhancer elements needed for consistent expression of lacZ (Lele and Wolgemuth, 2004). Within this region, consensus elements for several regulatory factors expressed in spermatocytes have been identified. Among them, A-myb (Latham et al., 1996) is reportedly expressed in mid- to late-stage spermatocytes, raising the possibility that it may be involved in the regulation of expression of Ccna1. We have also identified a 170-bp region within the promoter that is involved in repression of Ccna1 (Panigrahi et al., 2012). Within this region we identified cis-acting binding sequences for Sp1 and GATA1 transcription factors, neither of which is expressed in pachytene spermatocytes and later stages of germ cell differentiation. Notably, Sp1 is readily detected at earlier stages of spermatogenesis, suggesting that Sp1 acts as a suppressor of Ccna1 expression in spermatogonia. Supporting this hypothesis, we have also found occupancy of Sp1 on the Ccna1 promoter and influence of GATA1- 
dependent cis-acting elements in cell lines and most importantly, in spermatogonia (Panigrahi et al., 2012).

Transcription of the gene encoding Ccna2 is regulated by multiple factors in cell cycle-dependent manner and many of the DNA sequences mediating this regulation have been clearly delineated (reviewed in (Blanchard, 2000)). An in vivo footprinting study of nucleosomes on the mouse Ccna2 promoter revealed progressive loss of contact between histones and DNA synchronous with gene activation (Coisy et al., 2004). This nucleosomal organization is maintained by a bipartite repressor sequence, which is recognized by the chromatin remodeling factor Brahma/SNF2alpha. Other known repressors of Ccna2 promoter activity are E4F, which performs its function by binding the cyclic AMP response element site (Fajas et al., 2001), thyroid hormone receptor- $\beta 1$ (TR $\beta 1)$, which impairs the cyclin D/Rb/E2F pathway and prevents the recruitment of E2F1 to Ccna2 promoter thus exerting an antiproliferative action (Porlan et al., 2008) and Jun dimerization protein-2 JDP2, which is recruited directly to the promoter of Ccna2 at the AP-1 site (Pan et al., 2010). Cells lacking JDP2 showed elevated levels of Ccna2 mRNA. Furthermore, reintroduction of JDP2 resulted in the repression of transcription of Ccna2 and of cell-cycle progression.

In contrast to the extensive studies in cultured cells and to an extent in somatic tissues, almost nothing is known about the regulation of Ccna2 expression in the germ line. However, given its expression in primordial germ cells, varying stages of spermatogonial divisons, including the remarkably synchronous divisions of the differentiated $A 1$ to $B$ spermatogonial stages, and its absolute exclusion of expression once the cells make the decision to undergo meiosis, suggest that understanding its regulation at the level of both activation and repression will be of great interest.

\section{Events in cell cycle progression potentially downstream of cyclin A1/Cdk function}

We have previously reported the arrest point of cyclin A1deficient spermatocytes to late diplotene, just before entry into the first meiotic division (Nickerson et al., 2007). At this stage, the machinery for entry into M-phase, particularly the kinetochore, should be assembled. The kinetochore, the structural and functional organizing center of the centromere, begins with the assembly of the passenger protein complex in late prophase of meiosis. The components of this complex, identified in mitosis, are less thoroughly studied in meiosis. However, it is known that INCENP and aurora $\mathrm{B}$ localize to centromeric heterochromatin in late prophase (Parra et al., 2003) and become more concentrated at centromeres towards mid-metaphase. The activity of this complex is required for the phosphorylation of multiple targets. The aurora B kinase is thought to be involved in the spindle checkpoint and correct segregation of chromosomes, and disruption of the complex in mitotic cells causes mis-segregation of chromosomes (Lampson et al., 2004). The activity of MPF (cyclin B-Cdk1) has been linked in two ways to the passenger protein complex. Firstly, aurora A has been shown to be phosphorylated by MPF in Xenopus oocytes, ultimately leading to phosphorylation of histone $\mathrm{H} 3$ (Maton et al., 2003). Additionally, survivin, a powerful anti-apoptic protein, is phosphorylated by MPF at threonine 34, and this phosphorylation is protective against apoptosis in mitotic cells (O'Connor et al., 2000), making survivin a compelling candidate for sensing of meiotic arrest in cyclin A1-deficient mice. We also reported the localization of the cyclin A1 protein itself to the peri-centromeric region, leading to the hypothesis that cyclin $\mathrm{A} 1-\mathrm{Cdk}$ has a critical target(s) in this location.

\section{Impact of cyclin A mis-regulation on invertebrate spermato- genesis}

Drosophila melanogaster, where only a single homolog of the mammalian A-type cyclins has been found, is by far the simplest model system to investigate the role of this essential cyclin in the germline. Cyclin A is found at the site of the fusome, a branched germline specific organelle spanning through all cystocytes and connecting each at a single spindle pole centrosome (Lin et al., 1994). The fusome later regresses and becomes a spectrosome, which serves as a vehicle to transport material between cystocytes, including factors that determine the cell chosen to differentiate into an oocyte (Lilly et al., 2000). Overexpression of cyclin A in the cystocytes results in an extra round of mitotic divisions and cysts with 32 , rather than 16 , cells. In early stages of meiotic prophase in developing fly oocytes, cyclin A protein levels have been reported to be regulated at the posttranslational level by deadenylation of its mRNA (Morris et al., 2005). In addition, binding of the repressor Bruno to the cyclin A 3' UTR inhibited the translation of cyclin A during prophase of meiosis I and prevented return to the mitotic cycle (Sugimura and Lilly, 2006). As meiosis resumes during meiotic maturation, cyclin A mRNA is polyadenylated and the Bruno repressor is lost (Vardy et al., 2009). The de novo synthesized cyclin A protein is phosphorylated at multiple sites, likely involving autophosphorylation. The requirement for degradation of cyclin A by the ubiquitin ligase Effete in order to maintain the germline stem cells is an example of an evolutionary conserved mechanism to deplete mitotic cyclins (Chen et al., 2009).

In Drosophila testes the sub-cellular localization of cyclin A protein changes during the meiotic cell cycle. The cyclin A protein was mostly cytoplasmic in spermatocytes from early stages until the onset of the G2/M transition and prior to chromosome condensation (Gonczy et al., 1994). Early in the G2/M transition as the chromosomes underwent condensation cyclin A protein moved into the nucleus and was abruptly degraded just prior to metaphase I and was not detected in subsequent stages (Lin and Nash, 1996).

Very recently Yamashita and colleagues confirmed this rapid degradation prior to anaphase onset and also demonstrated that during mitotic divisions of male cystocytes cyclin A exhibits association with the fusome/spectrosome similar to that reported in the female germline (Yuan et al., 2012). This association also occurred during late $S$ to $\mathrm{G} 2$ stage of the cell cycle, an oscillatory pattern reminiscent of the periodic synthesis and degradation during the vertebrate cell cycle. As cells progressed through $\mathrm{G} 2$, the localization pattern changed dynamically by the release of cyclin $A$ into the cytoplasm and nucleus at the onset of mitosis and cyclin A protein levels remained comparable between the two compartments during prophase. Mutational analysis demonstrated that confinement of cyclin A to the centrosome in Drosophila germ stem cells is essential for correct sensing of centrosome mis-orientation. It is possible that there is an evolutionary conserved element of this function in male germ cells of higher organisms, which calls for a closer look at cyclin A localization.

\section{E-type cyclins}

During the past two decades, extensive research has dem- 
onstrated the importance of $E$ type cyclins in driving cell cycle progression by promoting the entry of the cell into S phase (Moroy and Geisen, 2004). Similar to the A-type cyclins, the family of mammalian E type cyclins is comprised of two proteins, E1 and E2. They show an amino acid similarity of $75 \%$ within the cyclin box and a $47 \%$ in the entire coding sequence and are co-expressed in almost all proliferating cell types studied (Moroy and Geisen, 2004). These characteristics, together with their concomitant activity during the mitotic cell cycle, suggest that E1 and E2 could have entirely overlapping functions. In proliferating somatic cells, transcription of cyclin E1 and E2 genes is induced by the E2F family of transcription factors at the end of G1. Later, a positive feedback mechanism confers the ability of cyclin E1 and E2 to stimulate their own transcription.

Cyclin E1 and E2 control cell proliferation by multiple mechanisms. Cyclin E-Cdk2 complexes also activate proteins involved specifically in the initiation of DNA replication, histone biosynthesis, centrosome duplication, gene expression control, pre-mRNAsplicing and cell cycle progression (reviewed in Yu and Sicinski, 2004), all in addition to the previously described kinase-independent functions (Geng et al., 2007). Possible functions of the $E$ type cyclins in non-proliferating cells have also been described: in the adult mouse brain, cyclin E1 forms complexes with Cdk5, controlling its activity in modulating synapse function and memory (Odajima et al., 2011).

Despite the importance of the E-type cyclins in the regulation of the mitotic cell cycle, mice that lack either cyclin E1 or E2 are fully viable with no apparent effect on cell proliferation in vitro (Geng et al., 2003). Cyclin E2-deficient males, however, are sub-fertile, with nearly a 4-fold reduction in the number of sperm and seminiferous tubules containing giant multinucleated cells, enlarged round spermatids, and delayed development of elongated spermatids (Geng et al., 2003, Wolgemuth, 2008). Mice lacking both E1 and E2 cyclins die early in embryogenesis and present a poorly developed layer of trophoblast giant multinucleated cells with reduced ploidies. This early embryonic lethality further obviates determining the effects of complete loss of E-type cyclins on spermatogenesis.

Although it is known that cyclin E1 and E2 are expressed in testis and the effect of E2 absence on male fertility indicates a pivotal role for this cyclin during spermatogenesis, the precise sites of expression have not been determined at the cellular level. To elucidate the function of the E-type cyclins during spermatogenesis, we have initiated collaborative studies with the Sicinski lab to determine the pattern of E1 and E2 expression in the testis and, using both conventional and conditional knockout strains of mice, to examine the consequences of complete lack of E-type function in the male germ line (Martinerie et al., 2013). Some early observations from these studies are highlighted below.

E2 mRNA and protein are readily detected in spermatocytes throughout prophase I (Fig. 2) (Martinerie et al., 2013). E1 mRNA can be detected in early meiotic prophase but $\mathrm{E} 1$ protein is seen only later in prophase and at lower levels than E2 (Fig. 2). Further characterization of the spermatogenic abnormalities in E2-deficient mice revealed abnormal loading of the synaptonemal complex proteins, persistent $\gamma \mathrm{H} 2 \mathrm{AX}$ foci in later prophase I stages, heterologous chromosome associations and chromosome rearrangements (Martinerie et al., 2012). A known catalytic partner for the E-type cyclins, Cdk2, is also expressed in meiotic prophase and required for meiotic progression (Ortega et al., 2003). As a consequence, it is possible that the cyclin E2-Cdk2 complexes are involved in phosphorylating proteins implicated in these meiotic prophase events. Curiously, in the adult mouse testis $\mathrm{E} 1$ protein is readily detected in the non-dividing Sertoli cells and at low levels during later stages of prophase I (Martinerie et al., 2013).

During Drosophila oogenesis, cyclin E is highly expressed in follicle stem cells and forms a complex with Cdk2 (Lilly and Spradling, 1996). Oscillating levels of cyclin E are critical for proper DNA replication and cell fate determination of the follicle cells, preventing their differentiation into meiotic cells. In addition, the activity of the cyclinE-Cdk2 complex is essential for maintenance of the follicle stem cell niche, acting as a positive regulator between cell cycle and niche retention (Wang and Kalderon, 2009).

$C$. elegans has a single gene, cye-1, encoding cyclin $E$ that forms a complex with $\mathrm{Cdk} 2$ and controls progression through the $\mathrm{G}_{1}$ phase of mitotic cells, such as vulval cells (Fay and Han, 2000). Similar to Drosophila, in C. elegans the cyclin E-Cdk2 complex, together with GLP-1 notch signalling, maintain the proliferative cell fate and cell cycle progression of the germline cells and prevents the entry of the cells into meiosis (Fox et al., 2011). In this sense, the cyclin E-Cdk2 complex acts as a critical regulator of stem cell maintenance and inhibits the switch from the mitotic into the meiotic cell cycle (Jeong et al., 2011).

In contrast, in Xenopus laevis, an E type cyclin plays a pivotal role during meiosis, especially in the control of metaphase/anaphase transition of meiosis II (Tunquist et al., 2002). Two cyclin $\mathrm{E}$ genes have also been described in the frog, cyclin E1 and cyclin E2, both of which are homologues of the mammalian cyclin E's (Chevalier et al., 1996). In eggs, cyclin E-Cdk2 is expressed and activated during meiosis II and can trigger metaphase arrest by acting as a cytostatic factor by inhibiting the anaphase promoting factor (APC) (Tunquist et al., 2002).

Overall, the genetic analyses of these model organisms indicate that E-type cyclins could play two distinct and opposite roles in gametogenesis. In arthropods and nematodes, cyclin E1 maintains the proliferative status of the germ stem cells. On the other hand, in chordates and more specifically, in vertebrates, E1 and E2 have a cell-cycle independent role in senescent cells while also controlling critical meiotic processes. Although the molecular network wherein $\mathrm{E} 1$ (and E2) regulates the G1-S transition in proliferating cells is common for almost all eukaryotes, the complexity exhibited by vertebrate gametogenesis requires a more complex cell cycle control network as compared to other eukaryotes.

\section{B type cyclins}

B type cyclins are essential for the transition of the cell from $\mathrm{G} 2$ to $\mathrm{M}$ phase and are pivotal for activating the major M-phase kinase Cdk1 (Satyanarayana and Kaldis, 2009). They form part of MPF, which regulates processes such as nuclear envelope fragmentation and spindle assembly. Several B type cyclin members are present in diverse organisms varying from yeast to mammals, with three specific B type cyclins described in vertebrates: B1, B2 and B3. The mouse genes encoding cyclins B1 and B2 (Ccnb1 and Ccnb2) share homology with the classic B type cyclin genes found in flies, worms, frogs, and mammals. In contrast, Ccnb3 has evolved independently from $B 1$ and $B 2$ genes and constitutes a separate and single gene conserved from teleost and nematodes to vertebrates.

Cyclin B1 and B2 are expressed in almost all organs that contain 
dividing cells. In general, the expression level of B2 in mitotic cells is lower than B1, except in the testis, where both $\mathrm{B} 1$ and $\mathrm{B} 2$ have similar expression levels (Brandeis and Hunt, 1996). In contrast, cyclin B3 is expressed only during meiosis in females and males (Nguyen et al., 2002). Cyclin B1 is essential for mouse embryonic development as B1-deficient mice die before embryonic day 10 . In contrast, B2-deficient mice are viable and females and males are fertile (Brandeis et al., 1998).

In the adult testis, we have shown that the three B type cyclins exhibit quite distinct patterns of expression (Fig. 2). Ccnb3 mRNA is expressed in early prophase stages, particularly leptotene and zygotene, and is detected at very low levels in pachytene spermatocytes (Nguyen et al., 2002). Later, Ccnb2 is expressed in meiotic prophase, particularly during pachytene and diplotene, although low levels of mRNA are also detected in early stage spermatids. In contrast, while Ccnb1 transcripts are also detected in spermatocytes, they are most abundant in post-meiotic spermatids (Chapman and Wolgemuth, 1992). Notably, neither B1 nor B2 were detected in mitotically dividing spermatogonia. Although in Drosophila and C. elegans cyclin B3 is expressed in both mitotic and meiotic germ line cells and play a role in promoting the entry of the cell from G2 to M phase (Deyter et al., 2010, Tarailo-Graovac and Chen, 2012), no endogenous cyclin B3 has been detected in cell lines from a wide variety of cell types (Nguyen et al., 2002).

The function of the B-type cyclins in spermatogenesis is still not fully understood. As noted above, loss of cyclin B2 had no effect on either male or female fertility but the embryonic lethality of cyclin B1-deficient mice precludes determining its function in either germ line. Use of a conditional knock out of cyclin B1 function specifically in the male germ line is needed to address this important question. Transgenic mice that express cyclin B3 after zygotene exhibited seminiferous tubules mostly depleted of germ cells and abnormal round spermatids, together with increased apoptosis and reduced sperm production (Refik-Rogers et al., 2006). It was thus suggested that down-regulation of cyclin B3 at the zygotene-pachytene transition is necessary for the normal progression of spermatogenesis (Refik-Rogers et al., 2006). Another interesting aspect of cyclin B3 function is that when partnered with Cdk2 in cell lines it forms kinase-deficient complexes (Nguyen et al., 2002). Based on this observation, we have previously suggested the novel possibility that cyclin B3 expression during the stages where homologous pairing, synapsis and double strand break repair is occurring, could be inhibiting any chance of spermatocyte entry into a precocious pachytene stage (Nguyen et al., 2002).

During mitosis, there is interplay between cyclin A2-Cdk1 and the cyclin B1/B2-Cdk1 complexes. Cyclin A2-Cdk1 triggers the activation and nuclear accumulation of $B 1-C d k 1$, which induces chromatin condensation during mitosis (Gong and Ferrell, 2010). Thus, cyclin A2 could help initiate mitosis through its effects on cyclin B1. The co-expression of cyclins B1, B2 and the meiosisspecific cyclin A1 during pachytene and diplotene suggests that a similar interplay could be occurring at the end of prophase I.

\section{D-type cyclins}

The three mammalian D type cyclins, D1, D2 and D3, govern the progression of cells from G1 to S-phase. However, in addition to their role in proliferation, the $D$ type cyclins have been implicated in other cellular events, including differentiation and apoptosis
(Satyanarayana and Kaldis, 2009). Although cyclin D1, D2 and D3 are highly homologous and evolutionarily conserved, they contain distinct structural motifs and are differentially regulated in several cell types (Mullany et al., 2008). D1-deficient mice present reduced body size and neurological abnormalities; depletion of D2 causes impaired pancreatic beta-cell and gonadal function; and depletion of D3 causes alterations in immune cell development (Mullany et al., 2008).

Cyclin D1, as well D2 and D3 are frequently deregulated in cancers such as leukemia, breast, prostate and hepatocarcinoma, representing a biomarker for disease progression (Musgrove et al., 2011). Interestingly, D-type cyclins, particularly D1 have been associated with testicular cancer (Bartkova et al., 1999) in addition to its premature expression in teratoma-susceptible mouse germ cells (Heaney et al., 2012).

The three D-type cyclins are differentially expressed during spermatogenesis (Fig. 2). While cyclin D1 mRNA is expressed principally in non-dividing Sertoli cells, D2 appears in pachytene and diplotene spermatocytes (Ravnik et al., 1995) as well as in spermatogonia in stage VIII of the seminiferous epithelium (Beumer et al., 2000). Cyclin D3 is expressed in differentiated Sertoli cells, spermatogonia and differentiated spermatids (Zhang et al., 1999). D2 and D3 are also expressed in the Leydig cells (Beumer et al., 2000).

Despite the potential role of D-type cyclins during spermatogenesis, depletion of different $D$ cyclin function in the mouse has not resulted in male sterility, although it was noted that D2-deficient mice exhibit hypoplastic testes (Sicinski et al., 1996). Similar to other cyclins such as B or E, it is possible that the D-type cyclins also have functional redundancy during spermatogenesis. As the complete loss of D-type cyclins is embryonic lethal (Kozar et al., 2004), the use of conditional knockouts specific to the germ line could provide significant insight into the consequences of complete loss of D-type cyclin function.

\section{Acknowledgements}

We thank Dirk de Rooij for helpful discussion and advice on precise identification of spermatogonial cell types. This work was supported by National Institutes of Health, Grant 5R01HD034915 (to D.J.W.), and The Lalor Foundation (to M.M.).

\section{References}

BARTKOVA, J., RAJPERT-DE MEYTS, E., SKAKKEBAEK, N.E. and BARTEK, J. (1999). D-type cyclins in adult human testis and testicular cancer: relation to cell type, proliferation, differentiation, and malignancy. J Pathol 187: 573-581.

BERTHET, C., ALEEM, E., COPPOLA, V., TESSAROLLO, L. and KALDIS, P. (2003). Cdk2 knockout mice are viable. Curr. Biol. 13: 1775-1785.

BEUMER, T.L., ROEPERS-GAJADIEN, H.L., GADEMAN, I.S., KAL, H.B. and DE ROOIJ, D.G. (2000). Involvement of the D-type cyclins in germ cell proliferation and differentiation in the mouse. Biol Reprod 63: 1893-1898.

BLANCHARD, J. (2000). Cyclin A2 transcriptional regulation: modulation of cell cycle control at the G1/S transition by peripheral cues [In Process Citation]. Biochem Pharmacol 60: 1179-1184.

BLOOM, J. and CROSS, F.R. (2007). Multiple levels of cyclin specificity in cell-cycle control. Nat Rev Mol Cell Biol 8: 149-160.

BLOW, J.J. and DUTTA, A. (2005). Preventing re-replication of chromosomal DNA Nat Rev Mol Cell Biol 6: 476-486.

BRANDEIS, M. and HUNT, T. (1996). The proteolysis of mitotic cyclins in mammalian cells persists from the end of mitosis until the onset of $\mathrm{S}$ phase. EMBO J 15: 5280-5289. 
BRANDEIS, M., ROSEWELL, I., CARRINGTON, M., CROMPTON, T., JACOBS, M.A., KIRK, J., GANNON, J. and HUNT, T. (1998). Cyclin B2-null mice develop normally and are fertile whereas cyclin B1-null mice die in utero. Proc Natl Acad Sci USA 95: 4344-4349.

CHAPMAN, D.L. and WOLGEMUTH, D.J. (1992). Identification of a mouse B-type cyclin which exhibits developmentally regulated expression in the germ line. Mol Reprod Dev 33: 259-269.

CHEN, D., WANG, Q., HUANG, H., XIA, L., JIANG, X., KAN, L. and SUN, Q. (2009). Effete-mediated degradation of Cyclin Ais essential for the maintenance of germline stem cells in Drosophila. Development 136: 4133-4142.

CHEVALIER, S., COUTURIER, A., CHARTRAIN, I., LE GUELLEC, R., BECKHELLING, C., LE GUELLEC, K., PHILIPPE, M. and FORD, C.C. (1996). Xenopus cyclin $\mathrm{E}$, a nuclear phosphoprotein, accumulates when oocytes gain the ability to initiate DNA replication. J Cell Sci 109 (Pt 6): 1173-1184.

COISY, M., ROURE, V., RIBOT, M., PHILIPS, A., MUCHARDT, C., BLANCHARD, J.M. and DANTONEL, J.C. (2004). Cyclin A repression in quiescent cells is associated with chromatin remodeling of its promoter and requires Brahma/SNF2alpha. Mol Cell 15: 43-56.

DE ROOIJ, D.G. and RUSSELL, L.D. (2000). All you wanted to know about spermatogonia but were afraid to ask. J Androl 21: 776-798.

DETTIN, L., RAVINDRANATH, N., HOFMANN, M.C. and DYM, M. (2003). Morphological characterization of the spermatogonial subtypes in the neonatal mouse testis. Biol Reprod 69: 1565-1571.

DEYTER, G.M., FURUTA, T., KURASAWA, Y. and SCHUMACHER, J.M. (2010). Caenorhabditis elegans cyclin $\mathrm{B} 3$ is required for multiple mitotic processes including alleviation of a spindle checkpoint-dependent block in anaphase chromosome segregation. PLoS Genet 6: e1001218.

FAJAS, L., PAUL, C., VIE, A., ESTRACH, S., MEDEMA, R., BLANCHARD, J.M., SARDET, C. and VIGNAIS, M.L. (2001). Cyclin A is a mediator of p120E4Fdependent cell cycle arrest in G1. Mol Cell Biol 21: 2956-2966.

FAY, D.S. and HAN, M. (2000). Mutations in cye-1, a Caenorhabditis elegans cyclin E homolog, reveal coordination between cell-cycle control and vulval development. Development 127: 4049-4060.

FOX, P.M., VOUGHT, V.E., HANAZAWA, M., LEE, M.H., MAINE, E.M. and SCHEDL, T. (2011). Cyclin E and CDK-2 regulate proliferative cell fate and cell cycle progression in the C. elegans germline. Development 138: 2223-2234.

GAEMERS, I.C., VAN PELT, A.M., VAN DER SAAG, P.T. and DE ROOIJ, D.G. (1996). All-trans-4-oxo-retinoic acid: a potent inducer of in vivo proliferation of growtharrested A spermatogonia in the vitamin A-deficient mouse testis. Endocrinology 137: 479-485

GENG, Y., LEE, Y.M., WELCKER, M., SWANGER, J., ZAGOZDZON, A., WINER, J.D., ROBERTS, J.M., KALDIS, P., CLURMAN, B.E. and SICINSKI, P. (2007). Kinase-independent function of cyclin E. Mol Cell 25: 127-139.

GENG, Y., YU, Q., SICINSKA, E., DAS, M., SCHNEIDER, J.E., BHATTACHARYA, S., RIDEOUT, W.M., BRONSON, R.T., GARDNER, H. and SICINSKI, P. (2003). Cyclin E ablation in the mouse. Cell 114: 431-443.

GONCZY, P., THOMAS, B.J. and DINARDO, S. (1994). roughex is a dose-dependent regulator of the second meiotic division during Drosophila spermatogenesis. Cell 77: 1015-1025.

GONG, D. and FERRELL, J.E., JR. (2010). The roles of cyclin A2, B1, and B2 in early and late mitotic events. Mol Biol Cell 21: 3149-3161.

HEANEY, J.D., ANDERSON, E.L., MICHELSON, M.V., ZECHEL, J.L., CONRAD, P.A., PAGE, D.C. and NADEAU, J.H. (2012). Germ cell pluripotency, premature differentiation and susceptibility to testicular teratomas in mice. Development 139: 1577-1586.

JEONG, J., VERHEYDEN, J.M. and KIMBLE, J. (2011). Cyclin E and Cdk2 control GLD-1, the mitosis/meiosis decision, and germline stem cells in Caenorhabditis elegans. PLoS Genet 7: e1001348.

KALASZCZYNSKA, I., GENG, Y., IINO, T., MIZUNO, S., CHOI, Y., KONDRATIUK, I., SILVER, D.P., WOLGEMUTH, D.J., AKASHI, K. and SICINSKI, P. (2009). Cyclin $A$ is redundant in fibroblasts but essential in hematopoietic and embryonic stem cells. Cell 138: 352-365.

KOZAR, K., CIEMERYCH, M.A., REBEL, V.I., SHIGEMATSU, H., ZAGOZDZON, A., SICINSKA, E., GENG, Y., YU, Q., BHATTACHARYA, S., BRONSON, R.T. et al., (2004). Mouse development and cell proliferation in the absence of D-cyclins. Cell 118: 477-491.
LAMPSON, M.A., RENDUCHITALA, K., KHODJAKOV, A. and KAPOOR, T.M. (2004). Correcting improper chromosome-spindle attachments during cell division. Nat Cell Biol 6: 232-237.

LATHAM, K.E., LITVIN, J., ORTH, J.M., PATEL, B., METTUS, R. and REDDY, E.P. (1996). Temporal patterns of A-myb and B-myb gene expression during testis development. Oncogene 13: 1161-1168.

LELE, K.M. and WOLGEMUTH, D.J. (2004). Distinct regions of the mouse cyclin A1 gene, Ccna1, confer male germ-cell specific expression and enhancer function. Biol Reprod 71: 1340-1347.

LIAO, C., LI, S.Q., WANG, X., MUHLRAD, S., BJARTELL, A. and WOLGEMUTH, D.J. (2004). Elevated levels and distinct patterns of expression of A-type cyclins and their associated cyclin-dependent kinases in male germ cell tumors. Int $J$ Cancer 108: 654-664.

LILLY, M.A., DE CUEVAS, M. and SPRADLING, A.C. (2000). Cyclin A associates with the fusome during germline cyst formation in the Drosophila ovary. Dev Biol 218: 53-63.

LILLY, M.A. and SPRADLING, A.C. (1996). The Drosophila endocycle is controlled by Cyclin E and lacks a checkpoint ensuring S-phase completion. Genes Dev 10: 2514-2526.

LIN, H., YUE, L. and SPRADLING, A.C. (1994). The Drosophila fusome, a germlinespecific organelle, contains membrane skeletal proteins and functions in cyst formation. Development 120: 947-956.

LIN, M. and NASH, H.A. (1996). Influence of general anesthetics on a specific neural pathway in Drosophila Melanogaster. Proc Natl Acad Sci USA 93: 10446-10451.

LIU, D., LIAO, C. and WOLGEMUTH, D.J. (2000). A Role for Cyclin A1 in the Activation of MPF and G2-M Transition during Meiosis of Male Germ Cells in Mice. Dev. Biol. 224: 388-400.

LIU, D., MATZUK, M.M., SUNG, K.W., GUO, Q., WANG, P. and WOLGEMUTH, D.J. (1998). Cyclin A1 is required for meiosis in the male mouse. Nature Genetics 20: 377-380.

MALUMBRES, M. and BARBACID, M. (2005). Mammalian cyclin-dependent kinases. Trends Biochem Sci 30: 630-641.

MARTINERIE, L., MANTEROLA, M., PANIGRAPH, S.K., SHANG, S.W.W., WEISBACH, M., VASILEVA, A., GENG, Y., SICINSKI, P. and WOLGEMUTH, D.J. (2013). Etype cyclins are key regulators of homologous pairing, synapsis and chromosome stability during mammalian spermatogenesis. In Preparation.

MATON, G., THIBIER, C., CASTRO, A., LORCA, T., PRIGENT, C. and JESSUS, C. (2003). Cdc2-cyclin B triggers H3 kinase activation of Aurora-A in Xenopus oocytes. J Biol Chem 278: 21439-21449.

MORIMOTO, H., KANATSU-SHINOHARA, M., TAKASHIMA, S., CHUMA, S., NAKATSUJI, N., TAKEHASHI, M. and SHINOHARA, T. (2009). Phenotypic plasticity of mouse spermatogonial stem cells. PLoS One 4: e7909.

MOROY, T. and GEISEN, C. (2004). Cyclin E. Int J Biochem Cell Biol 36: 1424-1439.

MORRIS, J.Z., HONG, A., LILLY, M.A. and LEHMANN, R. (2005). twin, a CCR4 homolog, regulates cyclin poly(A) tail length to permit Drosophila oogenesis. Development 132: 1165-1174

MULLANY, L.K., WHITE, P., HANSE, E.A., NELSEN, C.J., GOGGIN, M.M., MULLANY, J.E., ANTTILA, C.K., GREENBAUM, L.E., KAESTNER, K.H. and ALBRECHT, J.H. (2008). Distinct proliferative and transcriptional effects of the D-type cyclins in vivo. Cell Cycle 7: 2215-2224.

MULLER-TIDOW, C., READHEAD, C., COHEN, A.H., ASOTRA, K., IDOS, G., DIEDERICHS, S., CAUVET, T., YANG, R., BERDEL, W.E., SERVE, H. et al., (2003) Successive increases in human cyclin $\mathrm{A} 1$ promoter activity during spermatogenesis in transgenic mice. Int $J$ Mol Med 11: 311-315.

MURPHY, M., STINNAKRE, M.G., SENAMAUD-BEAUFORT, C., WINSTON, N.J., SWEENEY, C., KUBELKA, M., CARRINGTON, M., BRECHOT, C. and SOBCZAKTHEPOT, J. (1997). Delayed early embryonic lethality following disruption of the murine cyclin A2 gene. Nat Genet 15: 83-86. Erratum in Nat Genet 23: 481.

MUSGROVE, E.A., CALDON, C.E., BARRACLOUGH, J., STONE, A. and SUTHERLAND, R.L. (2011). Cyclin D as a therapeutic target in cancer. Nat Rev Cancer 11: 558-572.

NGUYEN, T.B., MANOVA, K., CAPODIECI, P., LINDON, C., BOTTEGA, S., WANG, X.Y., REFIK-ROGERS, J., PINES, J., WOLGEMUTH, D.J. and KOFF, A. (2002). Characterization and expression of mammalian cyclin b3, a prepachytene meiotic cyclin. J Biol Chem 277: 41960-41969. 
NICKERSON, H.D., JOSHI, A. and WOLGEMUTH, D.J. (2007). Cyclin A1-deficient mice lack histone $\mathrm{H} 3$ serine 10 phosphorylation and exhibit altered aurora $B$ dynamics in late prophase of male meiosis. Dev Biol 306: 725-735.

O'CONNOR, D.S., GROSSMAN, D., PLESCIA, J., LI, F., ZHANG, H., VILLA, A., TOGNIN, S., MARCHISIO, P.C. and ALTIERI, D.C. (2000). Regulation of apoptosis at cell division by p34cdc2 phosphorylation of survivin. Proc Natl Acad Sci USA 97: 13103-13107.

OATLEY, M.J., KAUCHER, A.V., RACICOT, K.E. and OATLEY, J.M. (2011). Inhibitor of DNA binding 4 is expressed selectively by single spermatogonia in the male germline and regulates the self-renewal of spermatogonial stem cells in mice. Biol Reprod 85: 347-356.

ODAJIMA, J., WILLS, Z.P., NDASSA, Y.M., TERUNUMA, M., KRETSCHMANNOVA, K., DEEB, T.Z., GENG, Y., GAWRZAK, S., QUADROS, I.M., NEWMAN, J. et al., (2011). Cyclin E constrains Cdk5 activity to regulate synaptic plasticity and memory formation. Dev Cell 21: 655-668.

ORTEGA, S., PRIETO, I., ODAJIMA, J., MARTIN, A., DUBUS, P., SOTILLO, R., BARBERO, J.L., MALUMBRES, M. and BARBACID, M. (2003). Cyclin-dependent kinase 2 is essential for meiosis but not for mitotic cell division in mice. Nat Genet 35: 25-31.

PAN, J., NAKADE, K., HUANG, Y.C., ZHU, Z.W., MASUZAKI, S., HASEGAWA, H., MURATA, T., YOSHIKI, A., YAMAGUCHI, N., LEE, C.H. et al., (2010). Suppression of cell-cycle progression by Jun dimerization protein-2 (JDP2) involves downregulation of cyclin-A2. Oncogene 29: 6245-6256.

PANIGRAHI, S.K., VASILEVA, A. and WOLGEMUTH, D.J. (2012). Sp1 Transcription Factor and GATA1 cis-Acting Elements Modulate Testis-Specific Expression of Mouse Cyclin A1. PLoS One 7: e47862.

PARRA, M.T., VIERA, A., GOMEZ, R., PAGE, J., CARMENA, M., EARNSHAW, W.C., RUFAS, J.S. and SUJA, J.A. (2003). Dynamic relocalization of the chromosomal passenger complex proteins inner centromere protein (INCENP) and aurora-B kinase during male mouse meiosis. J Cell Sci 116: 961-974.

PORLAN, E., VIDAURRE, O.G. and RODRIGUEZ-PENA, A. (2008). Thyroid hormone receptor-beta (TR beta 1) impairs cell proliferation by the transcriptional inhibition of cyclins D1, E and A2. Oncogene 27: 2795-2800.

RAVNIK, S.E., RHEE, K. and WOLGEMUTH, D.J. (1995). Distinct patterns of expression of the D-type cyclins during testicular development in the mouse. Dev Genet 16: 171-178.

RAVNIK, S.E. and WOLGEMUTH, D.J. (1996). The developmentally restricted pattern of expression in the male germ line of a murine cyclin A, cyclin A2, suggests roles in both mitotic and meiotic cell cycles. Dev Biol 173: 69-78.

RAVNIK, S.E. and WOLGEMUTH, D.J. (1999). Regulation of meiosis during mammalian spermatogenesis: the A-type cyclins and their associated cyclin-dependent kinases are differentially expressed in the germ-cell lineage. Dev. Biol. 207: 408-418.

REFIK-ROGERS, J., MANOVA, K. and KOFF, A. (2006). Misexpression of cyclin B3 leads to aberrant spermatogenesis. Cell Cycle 5: 1966-1973.

ROGULJA, D. and YOUNG, M.W. (2012). Control of sleep by cyclin A and its regulator. Science 335: 1617-1621.

SALLE, J., CAMPBELL, S.D., GHO, M. and AUDIBERT, A. (2012). CycA is involved in the control of endoreplication dynamics in the Drosophila bristle lineage. Development 139: 547-557.

SANTAMARIA, D., BARRIERE, C., CERQUEIRA, A., HUNT, S., TARDY, C., NEWTON, K., CACERES, J.F., DUBUS, P., MALUMBRES, M. and BARBACID, M. (2007). Cdk1 is sufficient to drive the mammalian cell cycle. Nature 448: 811-815.
SATYANARAYANA, A. and KALDIS, P. (2009). Mammalian cell-cycle regulation: several Cdks, numerous cyclins and diverse compensatory mechanisms. Oncogene 28: 2925-2939.

SICINSKI, P., DONAHER, J.L., GENG, Y., PARKER, S.B., GARDNER, H., PARK, M.Y., ROBKER, R.L., RICHARDS, J.S., MCGINNIS, L.K., BIGGERS, J.D. et al., (1996). Cyclin D2 is an FSH-responsive gene involved in gonadal cell proliferation and oncogenesis. Nature 384: 470-474.

SUGIMURA, I. and LILLY, M.A. (2006). Bruno inhibits the expression of mitotic cyclins during the prophase I meiotic arrest of Drosophila oocytes. Dev Cell 10: 127-135.

SWEENEY, C., MURPHY, M., KUBELKA, M., RAVNIK, S.E., HAWKINS, C.F., WOLGEMUTH, D.J. and CARRINGTON, M. (1996). A distinct cyclin A is expressed in germ cells in the mouse. Development 122: 53-64.

TARAILO-GRAOVAC, M. and CHEN, N. (2012). Proper cyclin B3 dosage is important for precision of metaphase-to-anaphase onset timing in Caenorhabditis elegans. G3 (Bethesda) 2: 865-871.

TUNQUIST, B.J., SCHWAB, M.S., CHEN, L.G. and MALLER, J.L. (2002). The spindle checkpoint kinase bub1 and cyclin e/cdk2 both contribute to the establishment of meiotic metaphase arrest by cytostatic factor. Curr Biol 12: 1027-1033.

VARDY, L., PESIN, J.A. and ORR-WEAVER, T.L. (2009). Regulation of Cyclin A protein in meiosis and early embryogenesis. Proc Natl Acad Sci USA 106: 1838-1843.

VERMEULEN, K., VAN BOCKSTAELE, D.R. and BERNEMAN, Z.N. (2003). The cell cycle: a review of regulation, deregulation and therapeutic targets in cancer Cell Prolif 36: 131-149.

WANG, X., GOMUTPUTRA, P., WOLGEMUTH, D.J. and BAXI, L.V. (2010). Acute alcohol exposure induces apoptosis and increases histone H3K9/18 acetylation in the mid-gestation mouse lung. Reprod Sci 17: 384-390.

WANG, Z.A. and KALDERON, D. (2009). Cyclin E-dependent protein kinase activity regulates niche retention of Drosophila ovarian follicle stem cells. Proc Natl Acad Sci USA 106: 21701-21706

WOLGEMUTH, D.J. (2008). Function of cyclins in regulating the mitotic and meiotic cell cycles in male germ cells. Cell Cycle 7: 3509-3513.

WOLGEMUTH, D.J. (2011). Function of the A-type cyclins during gametogenesis and early embryogenesis. Results Probl Cell Differ 53: 391-413.

YANG, R., MOROSETTI, R. and KOEFFLER, H.P. (1997). Characterization of a second human cyclin $A$ that is highly expressed in testis and in several leukemic cell lines. Cancer Res. 57: 913-920.

YU, Q. and SICINSKI, P. (2004). Mammalian cell cycles without cyclin E-CDK2. Cell Cycle 3: 292-295.

YUAN, H., CHIANG, C.Y., CHENG, J., SALZMANN, V. and YAMASHITA, Y.M. (2012). Regulation of cyclin A localization downstream of Par-1 function is critical for the centrosome orientation checkpoint in Drosophila male germline stem cells. Dev Biol 361: 57-67.

ZHANG, Q., WANG, X. and WOLGEMUTH, D.J. (1999). Developmentally regulated expression of cyclin D3 and its potential in vivo interacting proteins during murine gametogenesis. Endocrinology 140: 2790-2800.

ZWICKER, J., LUCIBELLO, F.C., WOLFRAIM, L.A., GROSS, C., TRUSS, M., ENGELAND, K. and MULLER, R. (1995). Cell cycle regulation of the cyclin A, cdc25C and cdc2 genes is based on a common mechanism of transcriptional repression. EMBO J 14: 4514-4522

ZWIJSEN, R.M., WIENTJENS, E., KLOMPMAKER, R., VAN DER SMAN, J., BERNARDS, R. and MICHALIDES, R.J. (1997). CDK-independent activation of estrogen receptor by cyclin D1. Cell 88: 405-415. 


\section{Further Related Reading, published previously in the Int. J. Dev. Biol.}

\section{Germline stem cells and sex determination in Hydra}

Chiemi Nishimiya-Fujisawa and Satoru Kobayashi

Int. J. Dev. Biol. (2012) 56: 499-508

Impaired meiotic competence in putative primordial germ cells produced from mouse embryonic stem cells Marianna Tedesco, Donatella Farini and Massimo De Felici

Int. J. Dev. Biol. (2011) 55: 215-222

Generation of germ-line chimera zebrafish using primordial germ cells isolated from cultured blastomeres and cryopreserved embryoids

Yutaka Kawakami, Rie Goto-Kazeto, Taiju Saito, Takafumi Fujimoto, Shogo Higaki, Yoshiyuki Takahashi, Katsutoshi Arai and Etsuro Yamaha

Int. J. Dev. Biol. (2010) 54: 1493-1501

mgm 1, the earliest sex-specific germline marker in Drosophila, reflects expression of the gene esg in male stem cells

Adrian Streit, Luca Bernasconi, Pavel Sergeev, Alex Cruz and Monica Steinmann-Zwicky Int. J. Dev. Biol. (2002) 46: 159-166

Differentiation of mouse primordial germ cells into female or male germ cells N Nakatsuji and S Chuma

Int. J. Dev. Biol. (2001) 45: 541-548

The meiotic specific synaptonemal complex protein SCP3 is expressed by female and male primordial germ cells of the mouse embryo

A D Di Carlo, G Travia and M De Felici

Int. J. Dev. Biol. (2000) 44: 241-244

5 yr ISI Impact Factor $(2011)=2.959$
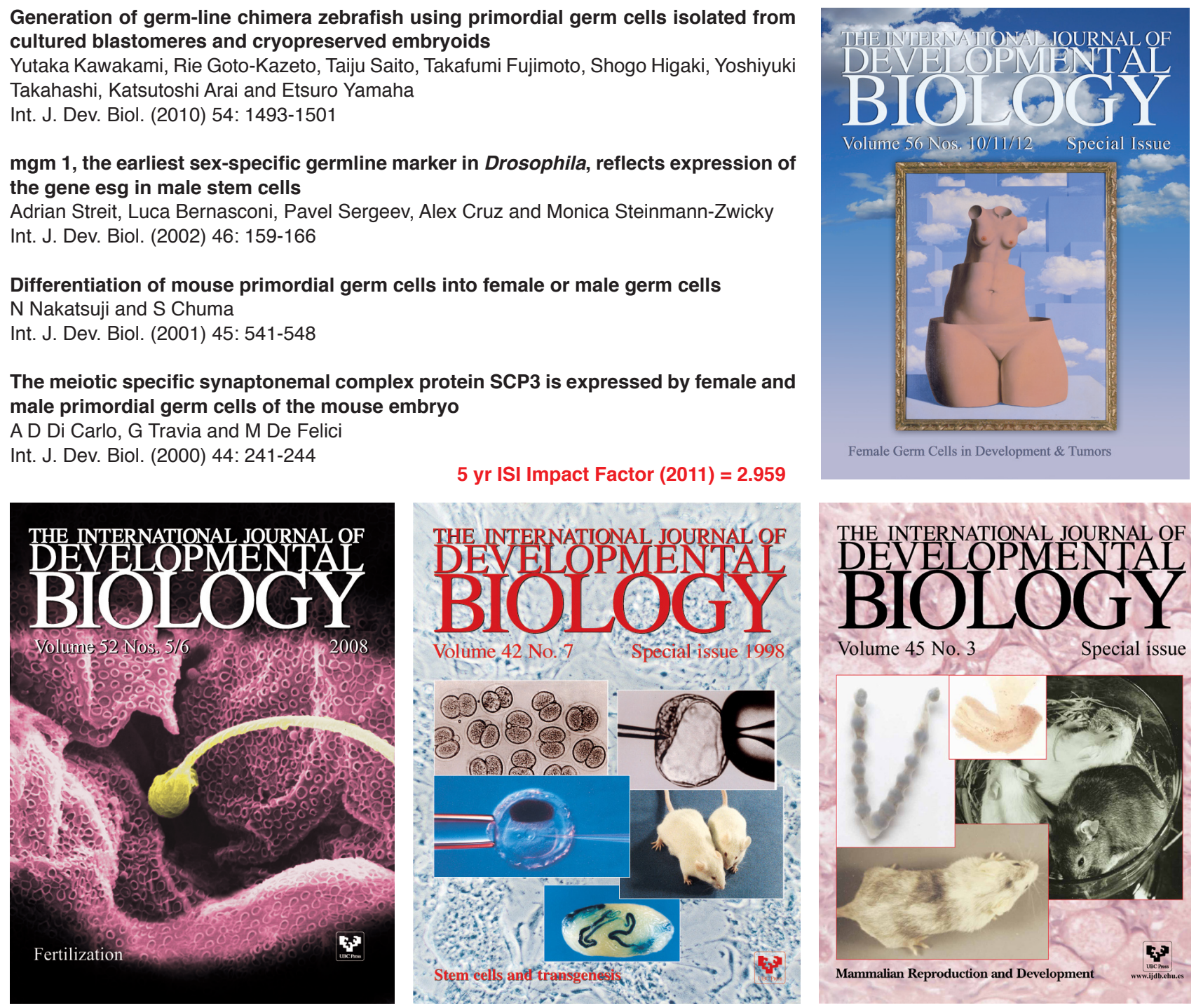